\title{
An Investigation Study on Optimizing Enterprise Resource Planning (ERP) Implementation in Emerging Public University: Al Baha University Case Study
}

\author{
Moh’D Suliman Shakkah $^{1}$, Khaled Alaqeel ${ }^{2}$, Ali Alfageeh ${ }^{3}$, Rahmat Budiarto ${ }^{4}$ \\ ${ }^{1}$ MIS Department, Faculty of Administrative and Financial Sciences Albaha University, Saudi Arabia \\ ${ }^{2}$ Ministry of Commerce \& Industry, AlKarj branch office, Saudi Arabia \\ ${ }^{3}$ Information Technology Center, Albaha University, Saudi Arabia \\ ${ }^{4}$ Smart Networked Computing Research Group, College of Comp. Sc. \& I.T., Albaha University, Saudi Arabia
}

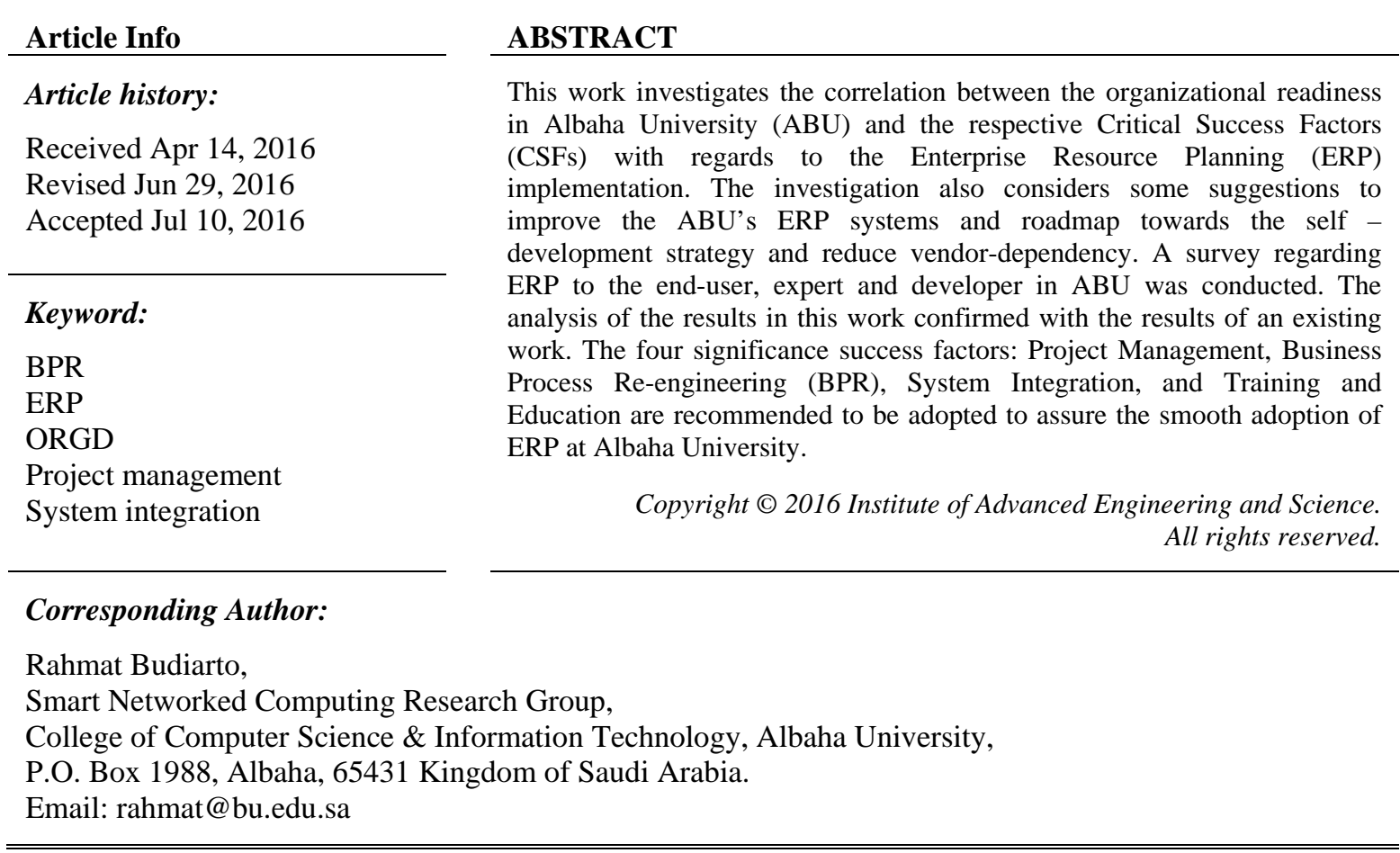

\section{INTRODUCTION}

The four critical success factors (CSFs) that helping to achieve effective implementation of Enterprise Resource Planning (ERP) projects are project management (PM), business process re-engineering (BPR), system integration (SI), and training and education (TED). The Organizational readiness (OGRD) is significantly and positively associated with these CFSs. Managerially, this knowledge can help in better planning, management and control of ERP projects [1].

In the other hand, a number of studies have been completed that look into the success / failure rates of IT projects in general [2],[3]. These studies indicate that serious problems exist across a broad crosssection of industries. A study of 5,400 large scale IT projects (projects with initial budgets greater than $\$ 15 \mathrm{M}$ ) conducted by McKinsey [4] finds that the well-known problems with IT Project Management are persisting. Among the key findings quoted from the report:

- 17 percent of large IT projects go so badly that they can threaten the very existence of the company

- On average, large IT projects run 45 percent over budget and 7 percent over time, while delivering 56 percent less value than predicted.

There are a number of interesting studies with statistics on project success rates, such as Standish Group's famous Chaos report garnered attention starting in the mid 90s, in particular based on very high reported project failure rates ( $\sim 90 \%$ are not successful). More recent data from their 2013 report shows improvement, but still only 39\% of projects are successful, with 61\% either 'failed' or 'challenged' [5]. 
The Information System and Application development in Albaha University is still progressing. The development of the Information Technology in general is not so encouraging, especially the development of ERP systems. Based on a study conducted internally in 2013, Albaha University (ABU) has the following problems.

- Low user satisfaction level

- No well communication between ITCenter and end user entity

- High vendor dependency

- Lack of IT awareness program

- Automation of many key process is partial

- Absence of documentation of the roles, responsibilities, and accountabilities

- Absence of well-defined organizational and process framework

- Limited IT standards and common policies and procedures.

At the same time, ABU has positive factors that are believed may support towards the improvement of the ERP systems. The positive factors include:

- Headway made by few departments by implementing ERP and student information system

- Enthusiasm to adopt e-working practices at departments/units/ centres

- There is a realization that more formalized oversight of IT is required and it needs to be a shared

- Good support from ABU top management to have best technology that help university to achieve their vision.

Research works have been conducted in ERP implementation such as Ramayah and Annamalai [6] that examined the benefits of two enterprises resource planning (ERP) packages namely SAP and Oracle. King [7] mentioned that the majority firms of any significant size are in some stages of implementing enterprise resources planning (ERP) systems or other similar multifunctional enterprise systems. Some are in the early stages of the process, where others have successfully implemented ERP and are tying these systems in supply-chain management and customer relationship management systems to have integrated systems. Voordijk et al. [8] held a study about large engineering consultancy firms in the Netherlands that have implemented ERP systems. Its purpose was to shed light on the changing role of information technology (IT) in these firms after implementing ERP. They used empirical case study research methodology, which was conducted by analyzing ERP implementations in ten Dutch-based engineering consultancy firms. Grossman \& Walsh [9] mentioned a lot of recommendations to ERP implementation as a huge mission full with risk. In this article a lot of practical advices for minimizing the risks. It looks at the technical, operational, and legal aspects of ensuring an acceptable ERP deployment. Along with the promise of having the latest technology that represented the best practices of many companies' prior to implementations of ERP systems, the software could be implemented in a shortened timeframe with less risk.

Organizational readiness for change is a multi-level, multi-faceted construct. As an organizationlevel construct, readiness for change refers to organizational members' shared resolve to implement a change (change commitment) and shared belief in their collective capability to do so (change efficacy). Organizational readiness for change varies as a function of how much organizational members value the change and how favorably they appraise three key determinants of implementation capability: task demands, resource availability, and situational factors. When organizational readiness for change is high, organizational members are more likely to initiate change, exert greater effort, exhibit greater persistence, and display more cooperative behavior. The result is more effective implementation [10].

This paper investigates the correlation between the organizational readiness in $A B U$ and the respective CSFs. Furthermore, the investigation also considers some suggestions to improve the ABU's ERP systems and roadmap towards the self -development strategy and reduce vendor-dependency.

\section{RESEARCH METHOD}

\subsection{Research hypotheses and the Conceptual model \\ 2.1.1. ORGD vs PM}

The OGRD for ERP employment within an organization is essential for early identification of probable problems that may affect the implementation outcome [11]. Tesch, et al., [12] emphasize the need to understand an organization's readiness before starting the project work. An organization that is ready for ERP implementation will have the PM capabilities and skills necessary to systematically manage the project to delivery. Such an organization will have established PM capabilities to plan execute and control project work. It is expected that OGRD will contribute significantly to the success of a number of project related activities. Hence, the following hypothesis is constructed.

HI: OGRD is positively and significantly associated (correlated) with the success of PM. 


\subsubsection{ORGD vs BPR}

A BPR exercise includes restructuring and redesigning the business processes of an organization to bring them into line with what are judged good-practice processes. De Soysa and Nanayakkara [13] note that $\mathrm{BPR}$ is an important component of the organization aware dimension of the overall organizational ERP readiness framework. Capaldo and Rippa [14] find out the BPR is to be one of the dimensions for OGRD for the implementation of ERP.

An organization that displays OGRD has the human resources and structural capabilities necessary to undertake various BPR related activities; including identifying any gaps between the existing business processes and routines, and the best-practice processes defined in generic ERP systems. This will help in estimating the efforts that may be required to re-engineer the existing processes, and the capabilities available within the organization to deal with undertaking a BPR exercise. These capabilities may include processmapping, process redesign and process documentation, among others. An OGRD exercise will also provide the organization with a broad understanding of the level and degree of required customization of an ERP system. Further, it will alert the organization to whether some processes cannot be modified due to particular business needs, such as the need to achieve competitive advantage. Overall. This demonstrates that OGRD could play a greater role in influencing the outcome of a BPR exercise. Thus, it is good to hypothesize the following.

H2: OGRD is positively and significantly associated (correlated) with the success of BPR.

\subsubsection{ORGD vs SI}

ERP systems are modular in structure and require inter-module interfacing and integration to work seamlessly. In addition, the strategic nature of ERP often necessitates its integration with systems outside its own platform. These could be the systems of partner(s), supplier(s), customer(s) and/or regulatory agencies. As a result, SI is one of the key strategies for successful ERP implementation [14],[15].

Furthermore, De Soysa and Nanayakkara [13] discovered that integrated resource management and data integrity to be important dimensions for organizational ERP readiness. Being organizationally ready entails having a good understanding of the number of legacy systems that will be closed or continued, due to the functional support (or lack thereof) of the to-be-implemented ERP system [14]. It also helps in gaining an understanding of the possible level of integration of ERP with partner business systems in the value chain. An understanding of staff proficiency in handling complex and sophisticated integration activities helps in devising appropriate plans for building capabilities to handle SI for successful ERP implementation. Based on the literature evidences and the previous discussions, it is meaningful to hypothesize:

H3: OGRD is positively and significantly associated (correlated) with the success of SI.

\subsubsection{ORGD vs TED}

Misra [16] emphasizes that an understanding of OGRD enables organizations to capture their users' training needs. Being ready can help organizations to gain a better understanding of the skill levels of their staff, and of the availability and adequacy of human resource skills and capabilities [17],[18]. It also helps in recognizing the available training facilities, trainer capabilities and training requirements for implementing a complex system like ERP. If required, organizations will be able to create plans for seeking trainers and consultancy services to provide an appropriate level of training to prospective ERP users. Organizations will then be able to make reasonably rational budget and timeframe estimates for the development of the training capabilities required to help users learn the ERP system. Hence, we contend that OGRD is helpful for providing an appraisal of the human and infrastructure capabilities that may be required to conduct TED successfully, and hence develop the following hypothesis.

H4: OGRD is positively and significantly associated (correlated) with the success of TED.

The proposed model was built based on the assumptions of the associated hypotheses: H1, H2, H3, and H4 as shown in Figure 1. 


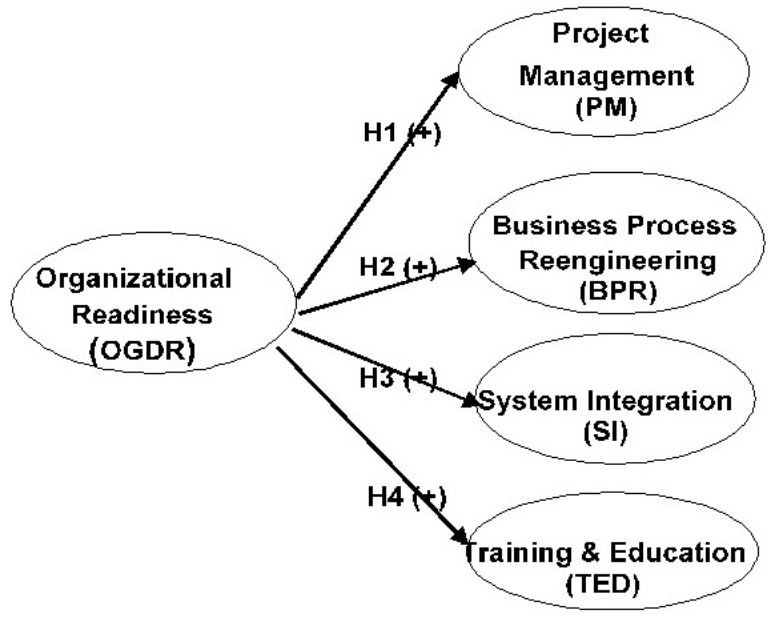

Figure 1. The conceptual ORGD - ERP model

\subsection{Instrument development and data collection}

A questionnaire with five-point Likert-type scale ranging from "strongly disagree" (1) to "strongly agree" (5) was used to collect data. The questionnaire was adapted from Ram et al., [1], five constructs: OGRD, PM, BPR, SI, and TED with their respected items were surveyed. The questionnaire was validated by experts, then translated to Arabic version forth and back and checked to be in the same levels.

The survey instrument was pre-tested in two phases, initially with academics. The feedback and comments received from both sets of respondents were incorporated to improve format, presentation, content clarity and questionnaire length. SPSS software was used with data and reliability were firstly checked, they were with good values. Demographic data are: End-users, Experts, and Developers.

\section{RESULTS AND ANALYSIS}

The distribution of respondents and respondent statistics is shown in Figure 2 and Table 1, respectively.

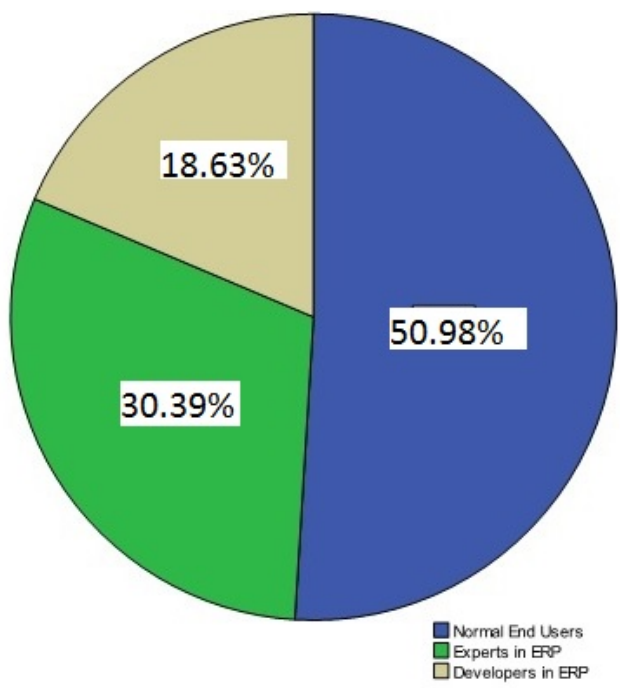

Tabel 1. Respondent statistics

\begin{tabular}{lcc}
\hline Number of & Valid & 102 \\
Respondent (N) & Missing & 0 \\
\hline Mean & & 1.68 \\
Std. Error of Mean & .077 \\
Median & 1.00 \\
Mode & 1 \\
Minimum & 1 \\
Maximum & 3 \\
Sum & 171 \\
\hline
\end{tabular}

Figure 2. Respondent distribution 


\subsection{Results}

Table 1 shows the respondent statistics. The Cronbach's Alpha test is 0.947 which means that the data provides high reliability (the Cronbach's Alpha >>> 0.7). Table 2 displays the statistics of all items of the structures, while Table 3 exhibits the reliability level of the collected data. This realibility will be shown or taken in total for the computed means of the constructs variables.

Table 2. Item-total statistics

\begin{tabular}{lcccc}
\hline & $\begin{array}{c}\text { Scale Mean if Item } \\
\text { Deleted }\end{array}$ & $\begin{array}{c}\text { Scale Variance if } \\
\text { Item Deleted }\end{array}$ & $\begin{array}{c}\text { Corrected Item-Total } \\
\text { Correlation }\end{array}$ & $\begin{array}{c}\text { Cronbach's Alpha if } \\
\text { Item Deleted }\end{array}$ \\
\hline PM1 & 64.91 & 213.665 & .611 & .946 \\
PM2 & 64.83 & 210.239 & .701 & .944 \\
PM3 & 64.94 & 211.244 & .741 & .944 \\
PM4 & 65.04 & 207.107 & .794 & .943 \\
PM5 & 65.10 & 211.733 & .603 & .946 \\
PM6 & 65.13 & 206.706 & .735 & .944 \\
BPR1 & 65.04 & 212.315 & .710 & .944 \\
BPR2 & 65.18 & 209.672 & .764 & .943 \\
BPR3 & 65.05 & 209.829 & .745 & .944 \\
SI1 & 65.19 & 210.767 & .684 & .944 \\
SI2 & 65.13 & 210.053 & .721 & .944 \\
SI3 & 65.05 & 209.354 & .754 & .943 \\
TED1 & 65.25 & 207.875 & .739 & .944 \\
TED2 & 64.71 & 213.477 & .564 & .946 \\
TED3 & 64.68 & 214.815 & .525 & .947 \\
TED4 & 64.88 & 212.639 & .605 & .946 \\
OGRD1 & 65.25 & 211.217 & .671 & .945 \\
OGRD2 & 65.31 & 211.208 & .647 & .945 \\
OGRD3 & 65.30 & 211.659 & .655 & .945 \\
OGRD4 & 65.17 & 213.606 & .494 & .948 \\
\hline & & & &
\end{tabular}

Table 3. Reliability Statistics

\begin{tabular}{ccc}
\hline Cronbach's Alpha & Cronbach's Alpha Based on Standardized Items & Number of Items \\
\hline .890 & .891 & 5 \\
\hline
\end{tabular}

The PM construct respondents gave an agreement with about $70 \%$ same was the following constructs: BPR, SI, TED, OGRD, as 68\%; 67\%; 72\%; 64\%, respectively (See Table 4).

Table 4. Item-total statistics

\begin{tabular}{|c|c|c|c|c|c|c|c|c|}
\hline & $\begin{array}{l}\text { Scale Mean if } \\
\text { Item Deleted }\end{array}$ & $\begin{array}{c}\text { Scale } \\
\text { Variance if } \\
\text { Item Deleted }\end{array}$ & $\begin{array}{c}\text { Corrected } \\
\text { Item-Total } \\
\text { Correlation }\end{array}$ & $\begin{array}{c}\text { Squared } \\
\text { Multiple } \\
\text { Correlation }\end{array}$ & $\begin{array}{c}\text { Cronbach's } \\
\text { Alpha if Item } \\
\text { Deleted }\end{array}$ & Mean & $\begin{array}{c}\text { Std. } \\
\text { Deviation }\end{array}$ & $\mathrm{N}$ \\
\hline PM construct & 13.5654 & 9.720 & .747 & .590 & .863 & 3.4886 & .90143 & 102 \\
\hline BPR construct & 13.6716 & 9.406 & .831 & .711 & .844 & 3.3824 & .88924 & 102 \\
\hline SI construct & 13.6944 & 9.385 & .779 & .634 & .855 & 3.3595 & .93659 & 102 \\
\hline TED Construct & 13.4534 & 9.983 & .661 & .486 & .882 & 3.6005 & .92961 & 102 \\
\hline OGRD Construct & 13.8309 & 9.943 & .650 & .438 & .885 & 3.2230 & .94849 & 102 \\
\hline
\end{tabular}

According to Table 5 we conclude that H1: There was a positively moderate association between PM and OGDR and it is significance (sig $<0.05$ ), so accept H1. 
Table 5. PM- ORGD Correlation

\begin{tabular}{|c|c|c|c|c|}
\hline & & & PM construct & OGRD Construct \\
\hline \multirow{6}{*}{ Spearman's rho } & \multirow{3}{*}{ PM construct } & Correlation Coefficient & 1.000 & $.585^{* *}$ \\
\hline & & Sig. (2-tailed) & . & .000 \\
\hline & & $\mathrm{N}$ & 102 & 102 \\
\hline & \multirow{3}{*}{ OGRD Construct } & Correlation Coefficient & $.585^{* *}$ & 1.000 \\
\hline & & Sig. (2-tailed) & .000 & . \\
\hline & & $\mathrm{N}$ & 102 & 102 \\
\hline
\end{tabular}

**. Correlation is significant at the 0.01 level (2-tailed).

Referring to Table 6 we conclude that H2: There was a positively moderate association between BPR and OGDR (sig < 0.05), so accept H2.

Table 6. BPR- ORGD Correlation

\begin{tabular}{|c|c|c|c|c|}
\hline & & & OGRD Construct & BPR construct \\
\hline \multirow{6}{*}{ Spearman's rho } & \multirow{3}{*}{ OGRD Construct } & Correlation Coefficient & 1.000 & $.573^{* *}$ \\
\hline & & Sig. (2-tailed) & . & .000 \\
\hline & & $\mathrm{N}$ & 102 & 102 \\
\hline & \multirow{3}{*}{ BPR construct } & Correlation Coefficient & $.573^{* *}$ & 1.000 \\
\hline & & Sig. (2-tailed) & .000 & . \\
\hline & & $\mathrm{N}$ & 102 & 102 \\
\hline
\end{tabular}

**. Correlation is significant at the 0.01 level (2-tailed).

Referring to Table 7 we conclude that H3: There was a positive moderate association between SI and OGDR, (sig < 0.05), so accept H3.

Table 7. SI- ORGD Correlation

\begin{tabular}{lllcc}
\hline & & & OGRD Construct & SI construct \\
\hline & & & 1.000 & $.651^{* *}$ \\
OGRD Construct & Correlation Coefficient &. & .000 \\
Spearman's rho & & $\mathrm{N}$ & 102 & 102 \\
& \multirow{2}{*}{ SI construct } & Correlation Coefficient & $.651^{* *}$ & .000 \\
& & Sig. (2-tailed) & .000 & 1.02 \\
\hline
\end{tabular}

**. Correlation is significant at the 0.01 level (2-tailed).

Referring to Table 8 we may conclude that H4: There was a Positive moderate association between TED and OGDR, (sig < 0.05), so accept H4.

Table 8. TED- ORGD Correlation

\begin{tabular}{cclcc}
\hline & & & OGRD Construct & TED Construct \\
\hline & \multirow{4}{*}{ OGRD Construct } & Correlation Coefficient & 1.000 & $.493^{* *}$ \\
& & Sig. (2-tailed) &. & .000 \\
Spearman's rho & $\mathrm{N}$ & 102 & 102 \\
& & Correlation Coefficient & $.493^{* *}$ & 1.000 \\
& TED Construct & Sig. (2-tailed) & .000 & $\cdot$ \\
& & $\mathrm{N}$ & 102 & 102 \\
\hline
\end{tabular}

**. Correlation is significant at the 0.01 level (2-tailed). 


\subsection{Analsyis}

Overall, the results show that OGRD is significantly and positively associated with the four investigated CSFs. The findings extend knowledge of the relationship among factors antecedent to different stages of ERP systems development [1]. Therefore, an understanding of OGRD at the adoption stage of an ERP system project is important because it influences both the adoption of ERP and the factors that themselves influence implementation. We discuss the detail findings in the following sub-sections.

\subsubsection{Effect of OGRD on PM}

The results indicate that OGRD is important for achieving the success of project-related work as it helps in better planning and control achieved through regular status meetings and realistic deadline for project work.

Albaha unversity IT Center management should assess a number of factors in order to understand the ORGD for PM. The factors include: information collection on in-house chage manaement procedures; organizational process assets for the management of risk, human resources, procurement and all stakeholders; the availibiity of previous project documents for reference in future projects; procedures and guidlines for preparing the business case of ERP projects; and the availability of PM software.

\subsubsection{Effect of OGRD on BPR}

The findings suggest that the university has to take advantage of the expertise and skills available within the university to prepare a BPR exercise. It will in turn help the university gains an understanding of the type and level of resources that need to be constructed in order to run the BPR.

\subsubsection{Effect of OGRD on SI}

The results say indirectly that possessing internal skills and resources is important to ensure SI activities are run easily. Consequently, the university should focus on the availability of a skilled workforce to support integrated interfaces. Albaha University is likely still rely on external support to maintain their integrated systems.

Albaha University IT center management should evaluate a number of factors, including: the experience and skill set of IT staff, particularly in SI; the availability of legacy in-house systems, and information about the systems that will continue to be used as well as the systems that are to be decommissioned; third-party information systems that need to be interfaced/ integrated with ERP; procedure and regulations for checking data integrity; and the availability of service providers and consultancy firms who can be engaged for SI tasks, whenever required. The evaluation will help to understand well ORGD for SI.

\subsubsection{Effect of OGRD on TED}

The study colcudes that the university should develop their staff skills, and foster a learning and sharing culture, for the effective management of training programs. The development of internal skills to achieve success in ERP prjects is also recommended, due to the fact that some organizational process may need unique training.

To understand OGRD for TED programmes, Albaha University management should assess a number of factors, including: the availability of trainers and their skill sets; the availability of training facilities; the allocated or required budget for training programmes; the availability of training materials from previous projects and the usefulness of any materials; the availability of an action plan for providing training to various levels of user; and a plan for evaluating the effectiveness of training programmes and feedback collection

\section{CONCLUSION}

The analysis of the results in this work confirmed with the results of work by Ram [1] that is the ORGD influences the success of ERP implementation. Alabaha University management need to study the university's organizational readiness to measure the technological, human, and infrastructure capabilities in designing and implementing ERP systems. The four significance critical success factors: PM, BPR, SI, and TED are recommended to be adopted to assure the smooth adoption of ERP at Albaha University.

\section{ACKNOWLEDGEMENTS}

The authors thank to Albaha University for the research funding under research contract no. 951436. 


\section{REFERENCES}

[1] J. Ram, et al., "Examining the role of organizational readiness in ERP project delivery," Journal of Computer Information Systems, vol/issue: 55(2), pp. 29-39, 2015.

[2] A. Subiyakto and A. R. Ahlan, "Implementation of Input-Process-Output Model for Measuring Information System Project Success,” TELKOMNIKA Indonesian Journal of Electrical Engineering, vol/issue: 12(7), pp. 5603-5612, 2014.

[3] A. Subiyakto, et al., "Measurement of Information System Project Success Based on Perceptions of the Internal Stakeholders," International Journal of Electrical and Computer Engineering (IJECE), vol/issue: 5(2), pp. 271279, 2015.

[4] M. Bloch, et al., "Delivering large-scale IT projects on time, on budget, and on value," available in McKansey\&Company website: http://www.mckinsey.com/insights/business_technology/ delivering_largescale_it_projects_on_time_on_budget_and_on_value, 2012.

[5] The Standish Group International, Inc., "Chaos manifesto 2013: Think Big, Act Small,” available online: http://www.versionone.com/assets/img/files/ChaosManifesto2013.pdf, 2013.

[6] C. Annamalai and T. Ramayah, "Enterprise resource planning (ERP) benefits survey of Indian manufacturing firms,” Business Process Management Journal, vol/issue: 17(3), pp. 495-509, 2011.

[7] W. R. King, "Ensuring ERP implementation success,” Information Systems Management, vol/issue: 22(3), pp. 8384, 2005.

[8] H. Voordijk, et al., "ERP and the changing role of IT in engineering consultancy firms," Business Process Management Journal, vol/issue: 11(4), pp. 418-430, 2005.

[9] T. T. Grossman and J. Walsh, "Avoiding the pitfalls of ERP system implementation," Information Systems Management, vol/issue: 21(2), pp. 38-42, 2004.

[10] B. J Weiner, “A theory of organizational readiness for change,” Implementation Science, vol/issue: 4(67), 2009. DOI: 10.1186/1748-5908-4-67.

[11] T. M. Somers, et al., "A taxonomy of players and activities across the ERP project life cycle," Information \& Management, vol/issue: 41(3), pp. 257-278, 2004.

[12] D. Tesch, et al., "IT project risk factors: The project management professionals' perspective,” Journal of Computer Information Systems, vol/issue: 47(4), pp. 61-70, 2007.

[13] S. de Soysa and J. Nanayakkara, "Readiness for ERP implementation in an organization: Development of an assessment model," Proceedings of International Conference on Information and Automation, Colombo, Sri Lanka, Dec 14-17, pp. 27-32, 2006.

[14] G. Capaldo and P. Rippa, “A planned-oriented approached for ERP implementation strategy selection,” Journal of Enterprise Information Management, vol/issue: 22(6), pp. 642-659, 2009.

[15] M. Al-Mashari, et al., "Enterprise resource planning: A taxonomy of critical factors," European Journal of Operational Research, vol/issue: 146(2), pp. 352-64, 2003.

[16] H. Misra, "Organisational readiness and its impact on ERP acquisition: A longitudinal study of an Indian dairy processing unit," Proceedings of the IEEE International Conference on Industrial Engineering and Engineering Management, Singapore, pp. 1719-23, 2008.

[17] M. Fathian, et al., "E-readiness assessment of non-profit ICT SMEs in a developing country: The case of Iran," Technovation, vol/issue: 28(9), pp. 578-90, 2008.

[18] J. Tan, et al., "Business-to-business adoption of eCommerce in China," Information \& Management, vol/issue: 44(3), pp. 332-51, 2007.

\section{BIOGRAPHIES OF AUTHORS}

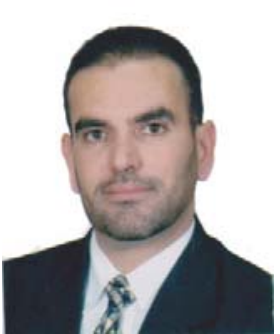

Moh'D Suliman Shakkah received BTMs. degree from Yarmouk University in 1998, M Information Technology in 2007 from USM University, and Dr. Information Technology (IS support decision) in 2012 from UUM University. Currently, he is an assistant professor at College of Administrative and Financial, Albaha University, Saudi Arabia. His research interests include developing smart IS Tools, ERP systems, Adoption and transferring Technology in developing counties, Recommendation systems support decisions. 


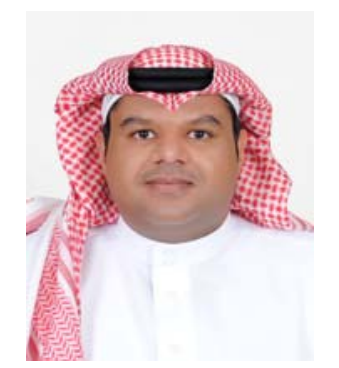

Khaled Alaqeel received B.Sc. in MIS degree from Baha College Of Science, Saudi Arabia in 2011, and M.A. in Business Administration with concentration in E-Business, from AlBaha University, Saudi Arabia in 2014. Currently, he is a Commercial Observation Manager at the Ministry of Commerce and Industry in AlKarj branch Saudi Arabia. His research interests include E-management, Business development, and E-commerce.

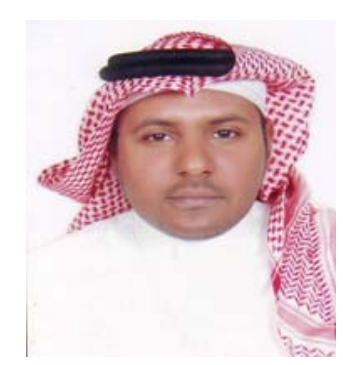

Ali Alfageeh received B.Sc. degree from King Khalid University in 2006. Currently, he is a system analysis at IT Center, Albaha University.

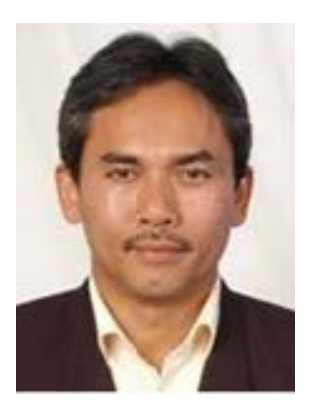

Rahmat Budiarto received B.Sc. degree from Bandung Institute of Technology in 1986, M.Eng, and Dr.Eng in Computer Science from Nagoya Institute of Technology in 1995 and 1998 respectively. Currently, he is a professor at College of Computer Science and IT, Albaha University, Saudi Arabia. His research interests include enterprise systems, IPv6, network security, Wireless sensor networks and smart networks. 